\title{
EFFECT OF MATERIAL TYPE ON THE STRESS DISTRIBUTION IN POSTERIOR THREE-UNIT FIXED DENTAL PROSTHESIS: A THREE-DIMENSIONAL FINITE ELEMENT ANALYSIS
}

\author{
Mazen A. Attia *
}

\begin{abstract}
Statement of the problem. Selection of the proper prosthetic restorative material is still a dilemma facing most of the clinicians.

Purpose. The aim of this study was to evaluate the effect of different framework materials on the stress distribution in a posterior three-unit fixed dental prosthesis.

Materials and methods. One 3D finite element model was specially prepared by scanning a model of a fixed dental prosthesis (FDP) in the posterior region. The model had missing maxillary first bicuspid and prepared abutments, that representing maxillary cuspid and second bicuspid. The model was simulated as restored by three different materials; Nickel-Chromium (Ni-Cr), Zirconia and Bio-HPP (PEEK). The model was subjected to compressive vertical load of $200 \mathrm{~N}$ applied at the central fossa of the pontic. Von Mises stress values were determined.
\end{abstract}

Results. Three linear static analyses were carried out. Stress and deformation fields generated under applied load were compared. Location of both maximum Von Mises stress and maximum total deformation were found on the abutment finish line towards the pontic.

Conclusion. Special attention should be considered to the finish line contact with fixed dental prosthesis to avoid stress concentration. Tooth may be insensitive to fixed dental prosthesis materials.

\section{INTRODUCTION}

Patients with a single missing posterior tooth can be treated with implant-supported crowns, conventional fixed dental prosthesis (FDPs), resinbonded fixed dental prosthesis (RBFDPs), and removable partial dentures. ${ }^{(1)}$ For many patients and clinicians, the prosthetic restoration of missing posterior teeth by means of a 3-unit conventional (FDP) is preferred. Survival rates of these (FDPs) were $77.8-89.2 \%$ after 10 years. ${ }^{(2,3)}$

The selection of a prosthetic restorative material depends on its ability to withstand the masticatory

\footnotetext{
* Lecturer of Fixed Prosthodontics, Beni Suef University, Egypt.
} 
forces and its esthetic outcome. ${ }^{(4)}$ For many years, metal-ceramic restorations are considered the gold standard in the prosthetic field because of their predictable structural performance, versatility, and low cost. ${ }^{(5)}$ Despite the success of metal-ceramic restorations, zirconia-ceramic restorations have been introduced as an alternative option to metalceramics inposterior three-unit (FDPs) because of their excellent biocompatibility, superior mechanical properties and enhanced esthetics; ${ }^{(6-8)}$ however, fracture of the framework especially in the connector area and chipping of the veneering ceramic are considered the main drawback of these restorations. ${ }^{9,10)}$

In contrast to ceramics, BioHPP; (bioactive high performance polymer containing 20\% ceramic fillers) based on polyetheretherketone (PEEK) has been introduced in dentistry. ${ }^{(1)}$ This thermoplastic material is characterized by excellent biocompatibility, good wear resistance, chemical stability, low weight and adequate mechanical properties enabling it to be a suitable alternative to ceramic restorations. ${ }^{(12,13)}$ The modulus of elasticity of this material is $4 \mathrm{GPa}$, close to that of bone, enabling it to act as a shock absorber; thus, reducing the forces transmitted to the restoration and the tooth root accordingly. ${ }^{(14)}$

The stress distribution in a (FDP) depends mainly on its material properties and geometric configuration. (15) The elastic modulus of the material is an important parameter for evaluation of aprosthetic restoration. Ideally, a restorative material should have a modulus of elasticity close to that of the tooth structure to obtain a more uniform stress distribution. However; the tooth consists of enamel and dentin, both of which have very different composition and elasticities. (16) According to Möllers et al. ${ }^{(9)}$ the framework design and material properties of the superstructure had a significant role in stress distribution. Borb et al..$^{(10)}$ also revealed that stress distribution was influenced by the type of ceramic used for the infrastructure.

Several techniques have been used to investigate the effect of dental restorative materials on stress distribution in dental prosthesis such as strain gauge analysis, photoelastic stress analysis, laser beam analysis and finite element analysis. ${ }^{(9,17)}$ Finite element analysis (FEA) has been employed by many investigators due to its accuracy, efficiency, time saving and low cost to evaluate mechanical behavior in complex structures such as implants, onlays, crowns and (FDPs). ${ }^{(18)}$

In this approach, the selected structure is divided into smaller elements which can be easily calculated on a computer. When an element is under pressure, based on the pre-definedmechanical properties of each element, its shape will be changed .These elements are connected to each other via nodesand, as a result, the total structure is affected. Becauseof the complexity of both the prosthesis and the tooth structure, the resulting changeson each surface caused by the applied forces can be determinedby adopting finite element analysis. ${ }^{(19)}$ The aim of this study was to evaluate the effect of different framework materials on the stress distribution in posterior three-unit fixed dental prosthesis.

\section{MATERIALS AND METHODS:}

A plaster model based on a clinical condition with a missing maxillary first bicuspid was prepared. The maxillary cuspid and maxillary second bicuspid were prepared to the dimensions of $4.5 \mathrm{~mm}$ height; assuming $2 \mathrm{~mm}$ flat occlusal reduction, with a uniform 120 degrees circumferential chamfer finish line of $1.2 \mathrm{~mm}$ width, and an axial taper angle of 6 degrees.

A 3D finite element model was constructed by 3D scanning a (simulating FDP). The (FDP) geometry was acquired by using 3D scanner (Roland Modela-model MDX-15-Roland DG Corporation of Hamamatsu, Japan) and computer graphics 
program (Roland's Dr. PICZA $3^{\mathrm{TM}}$ software), utilizing Roland Active Piezoelectric Sensor. Such scanner produced data file containing a cloud of points coordinates (Figure 1).

An intermediate, software was required (Rhino 3.0 - McNeelinc., Seattle, WA, USA) to trim a newly created surface by the acquired points. Finally, the (FDP) outer surface was closed and filled from its bottom to generate volume representing solid (FDP). Then, the solid (FDP) geometry was exported to finite element program as STEP file format. The same process was repeated for supporting bone and prepared abutments. Cement layer of $40 \mu \mathrm{m}$ was created by scaling the prepared abutments prior to using set of Boolean operations (subtract, cut, ... etc.) to keep the cement layer only.

The materials used in this study were assumed to be homogenous, isotropic and to possess linear elasticity, and its properties were listed in (Table 1). All the components (tooth, cement layer, FDP) of the model were exported as STEP files, and imported into finite element package ANSYS Workbench version 16 (ANSYS Inc., Canonsburg, PA, USA) to be assembled and analyzed.

The parabolic tetrahedral element was used meshing the model. That increasing the mesh density will improve the results accuracy for the discrete model. Mesh density of all model components is presented in (Table 2. Figure 2) illustrate the model of (FDP) on ANSYS screen, while (Figure 3) showed meshed component.

The solid modeling and finite element analysis (linear static analysis) were performed on Workstation HP Z820, with Dual Intel Xeon E52660, $2.2 \mathrm{GHz}$ processors, 64GB RAM. Three runs were performed, using three different (FDP) materials. A compressive load of $200 \mathrm{~N}$ was applied on the central fossa of the pontic, while the model base was fixed as a boundary condition.
TABLE (1) Material properties imported to the Finite Element program

\begin{tabular}{|c|c|c|}
\hline Material & $\begin{array}{c}\text { Young's modulus } \\
{[\mathrm{MPa}]}\end{array}$ & $\begin{array}{c}\text { Poisson's } \\
\text { ratio }\end{array}$ \\
\hline Base: Dentin & 18,600 & 0.31 \\
\hline $\begin{array}{c}\text { Resin cement (RelyX) } \\
(40 \mu \mathrm{m} \text { Cement Layer) }\end{array}$ & 8,000 & 0.30 \\
\hline (FDP) Materials & & \\
\hline Ni-Cr & 206,000 & 0.33 \\
Zirconia & 200,000 & 0.31 \\
$($ PEEK) & 3,600 & 0.37 \\
\hline
\end{tabular}

TABLE (2) The used mesh density

\begin{tabular}{|c|c|c|}
\hline & Nodes & Elements \\
\hline Base: Dentin (Cortical \& Spongy) & 160,908 & 93,785 \\
\hline Cement layer $(40 \mu \mathrm{m})$ & 93,591 & 54,503 \\
\hline (FDP) & 58,240 & 28,971 \\
\hline Total & 312,739 & 177,259 \\
\hline
\end{tabular}

TABLE (3) Summary of total deformation [mm]

\begin{tabular}{|c|c|c|c|}
\hline & Bone & Cement & (FDP) \\
\hline Ni-Cr & 0.005454 & 0.005532 & 0.016848 \\
\hline Zirconia & 0.005471 & 0.005550 & 0.017386 \\
\hline (PEEK) & 0.012099 & 0.013064 & 0.689750 \\
\hline
\end{tabular}

TABLE (4) Listing of maximum Von Mises stress [MPa]

\begin{tabular}{|c|c|c|c|}
\hline & Bone & Cement & (FDP) \\
\hline Ni-Cr & 4.220 & 4.538 & 417.18 \\
\hline Zirconia & 4.227 & 4.560 & 422.29 \\
\hline (PEEK) & 3.925 & 9.818 & 406.18 \\
\hline
\end{tabular}




\section{RESULTS}

The results of deformations and stresses appeared on prepared teeth indicated that maximum deformation appeared on the highest surface(s) of the prepared teeth, while maximum stresses appeared at the finish line towards the missing tooth (pontic).

Stresses in the FDPs: In terms of total deformation on the framework itself, the highest value was $(689 \mu)$ for (PEEK), followed by zirconia $(17.3 \mu)$, and the smallest deformation was $(16.8 \mu)$ for (Ni-Cr). Contrarily, the Von Mises stress values were (422 MPa) for zirconia, (417 MPa) for (Ni$\mathrm{Cr}$ ), and (406 MPa) for (PEEK) (Figures 4-6).

Stresses in the cement layer: Cement layer under rigid (FDPs) (Ni-Cr and Zirconia) deformed (compressed) by about (5 $\mu)$ that was doubled to be $(12 \mu)$ microns under resilient(FDP)(PEEK).Similar trend was found with Von Mises stress values that altered from (4.5 to $9.8 \mathrm{MPa})$ under rigid and resilient (FDP) materials, respectively (Figure.7).

Stresses on the prepared abutments: Rigid (FDP) materials (Ni-Cr and Zirconia) induced total deformation in the prepared abutments of order $(5.5 \mu)$, while the resilient one (PEEK) induced about $(12 \mu)$. On the other hand, Von Mises stress values seemed to be insensitive to (FDP) material even with relatively lower Von Mises stress of order $10 \%$ under (PEEK) (FDP) in comparison to rigid ones (Ni-Cr and Zirconia) (Figures8-10). Tables 3 and 4 lists the maximum values of total deformation and Von Mises stress, respectively.

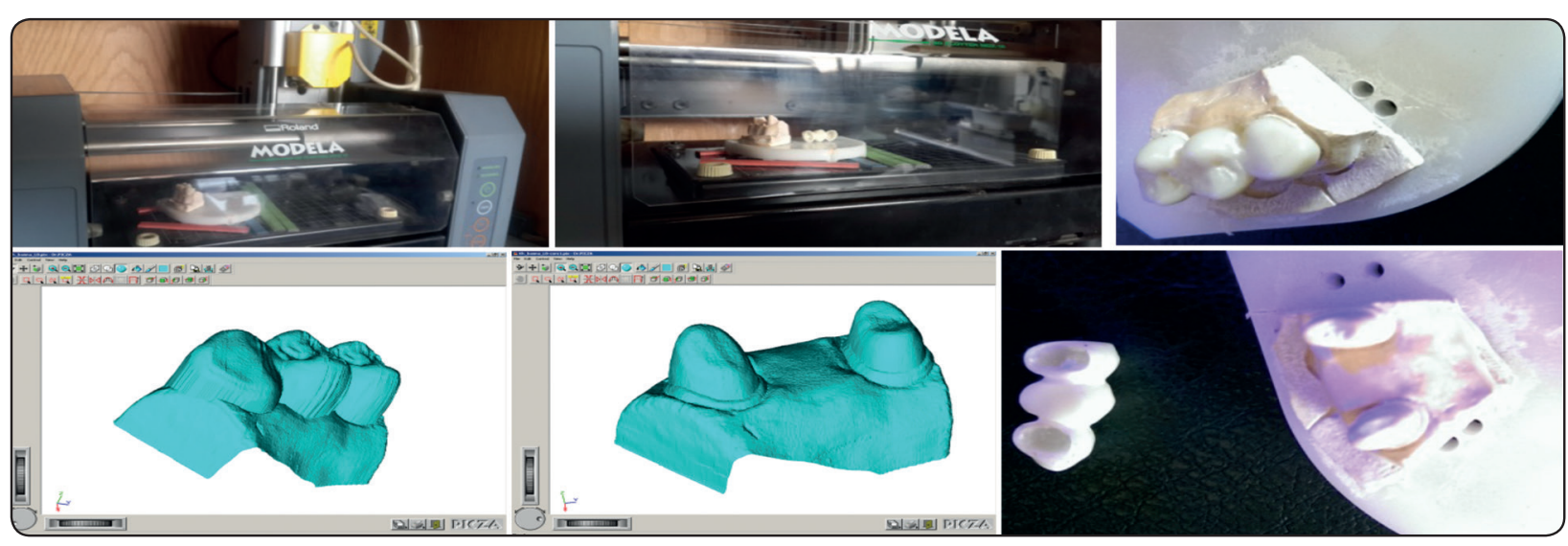

Fig. (1) Fixed partial denture during scanning.

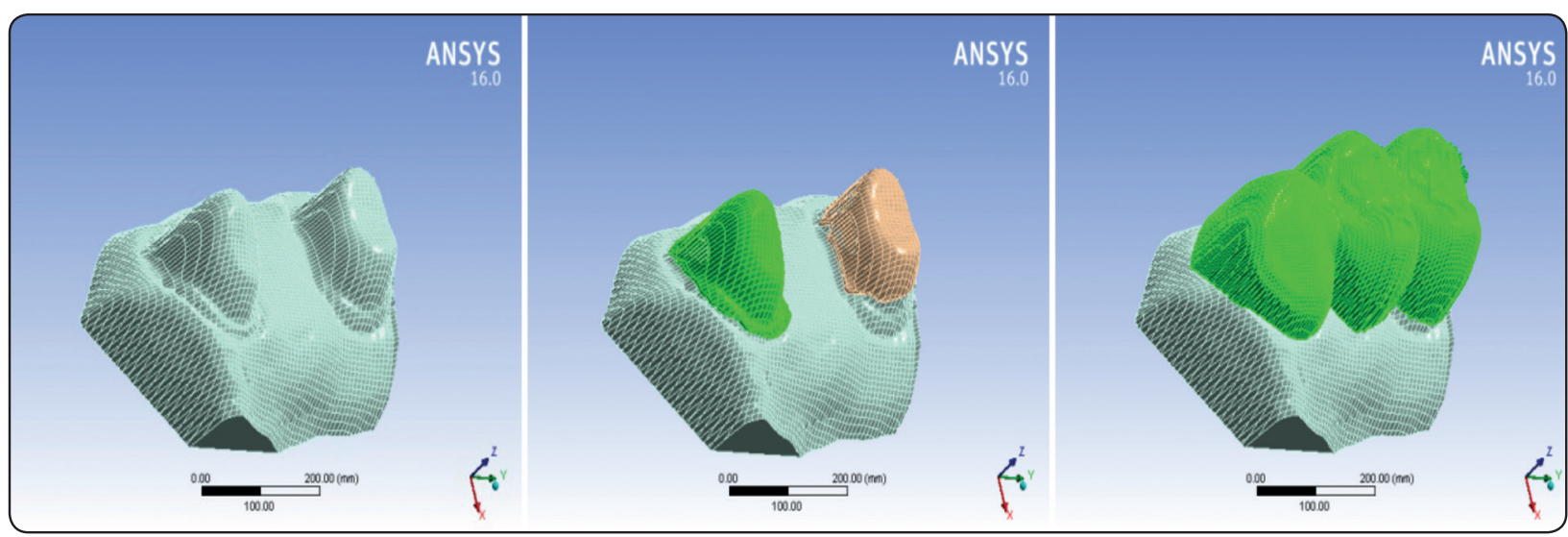

Fig. (2) Fixed dental prosthesis component during assembly (ANSYS screen shots). 


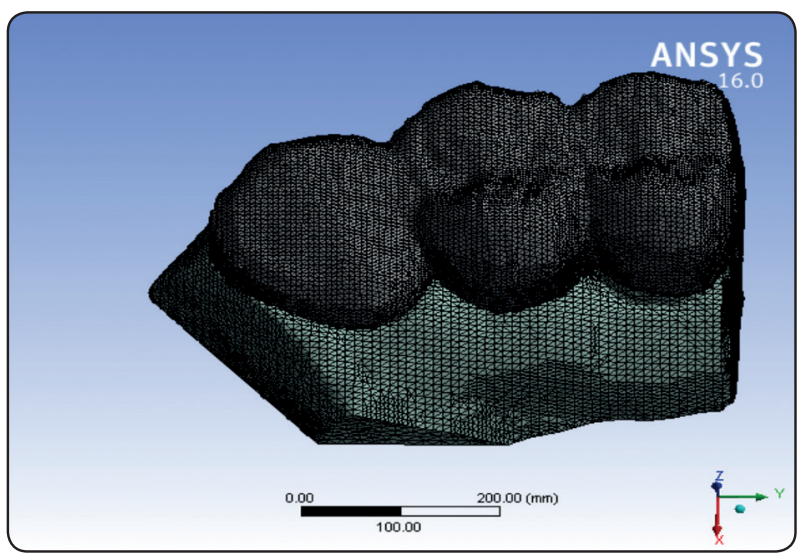

Fig. (3) Meshed Partial denture after assembly (ANSYS screen shots).

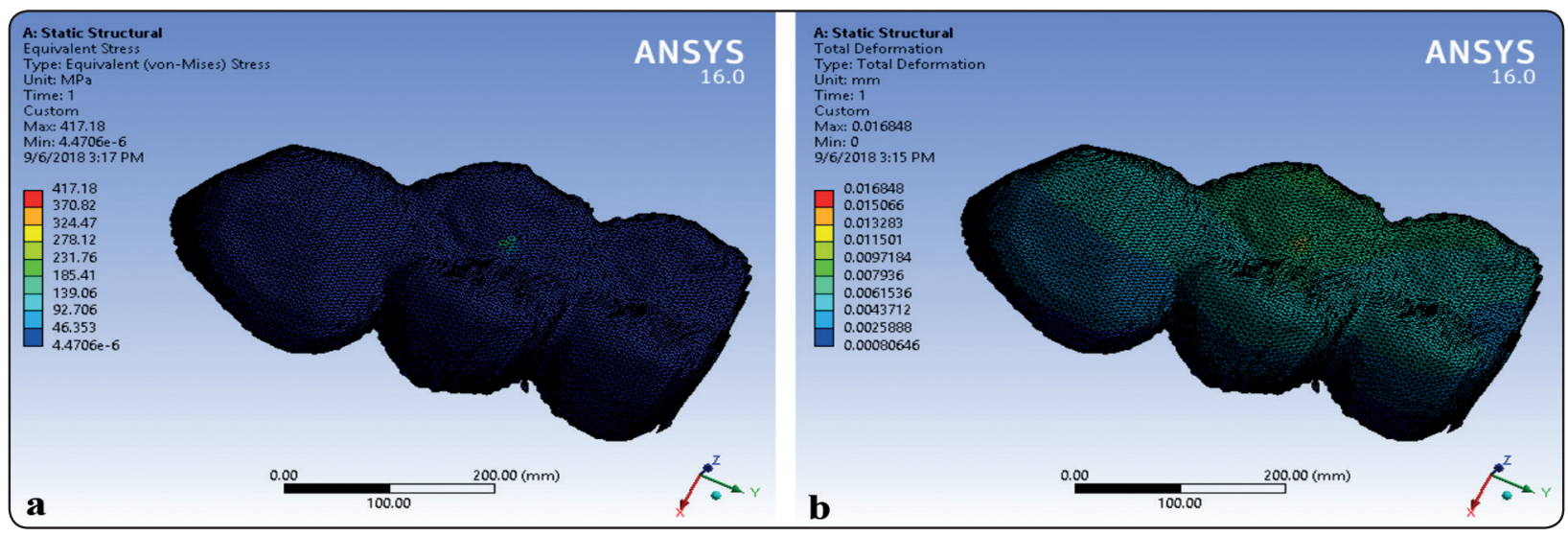

Fig. (4) Ni-Cr (FDP), (a) Von Mises stress and (b) total deformation.

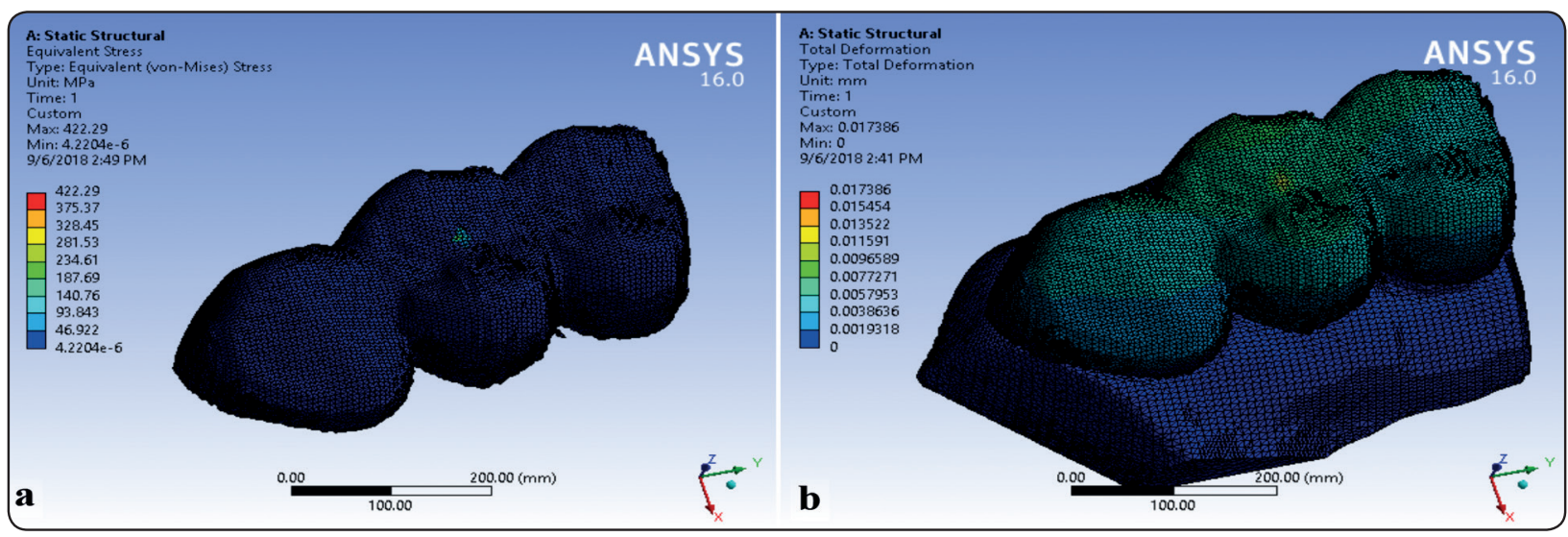

Fig. (5) Zircon (FDP), (a) Von Mises stress and (b) total deformation. 


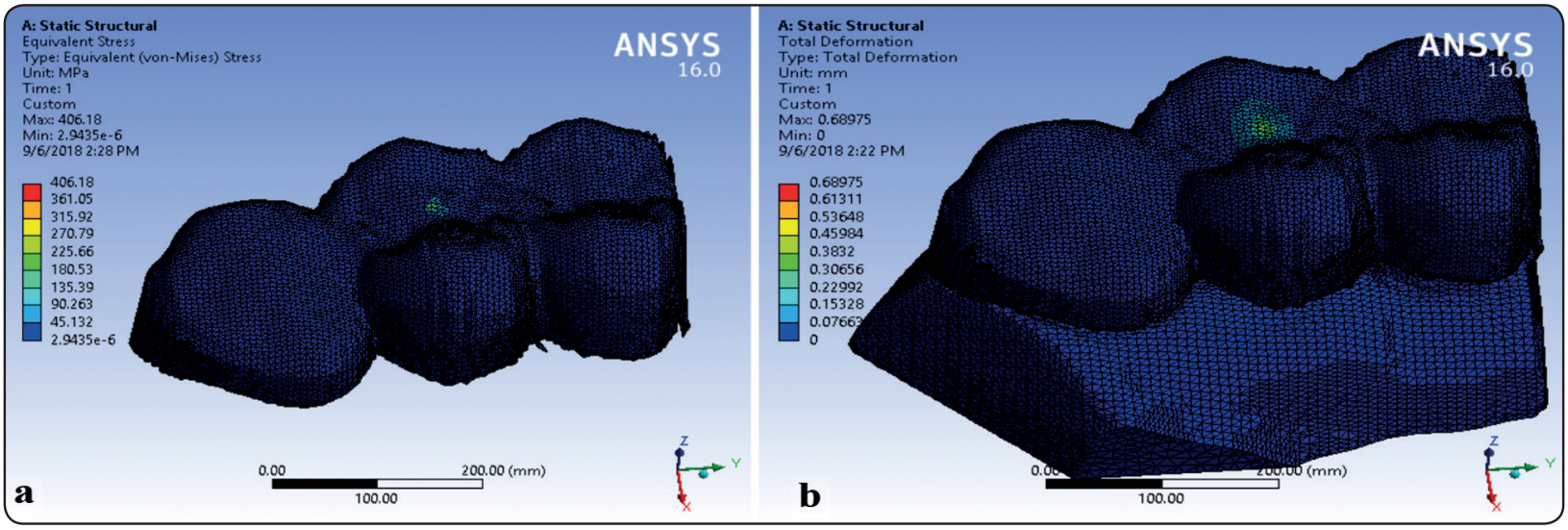

Fig. (6) PEEK (FDP), (a) Von Mises stress and (b) total deformation.

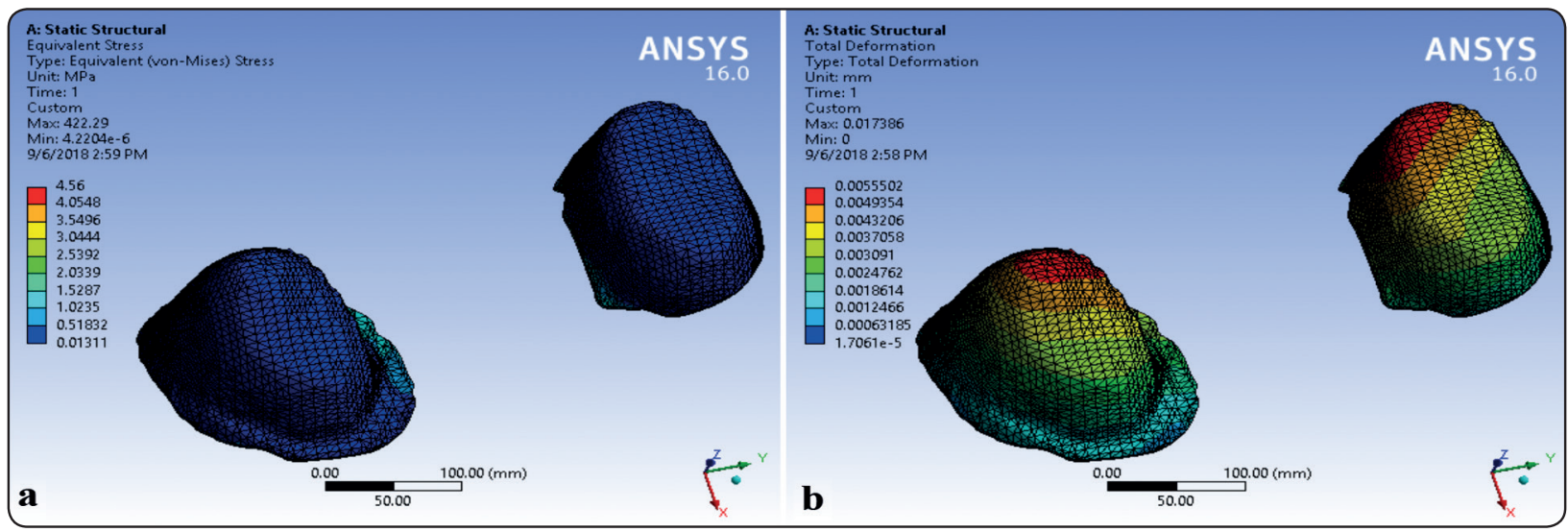

Fig. (7) Cement layer under Zirconia (FDP), (a) Von Mises stress and (b) total deformation.

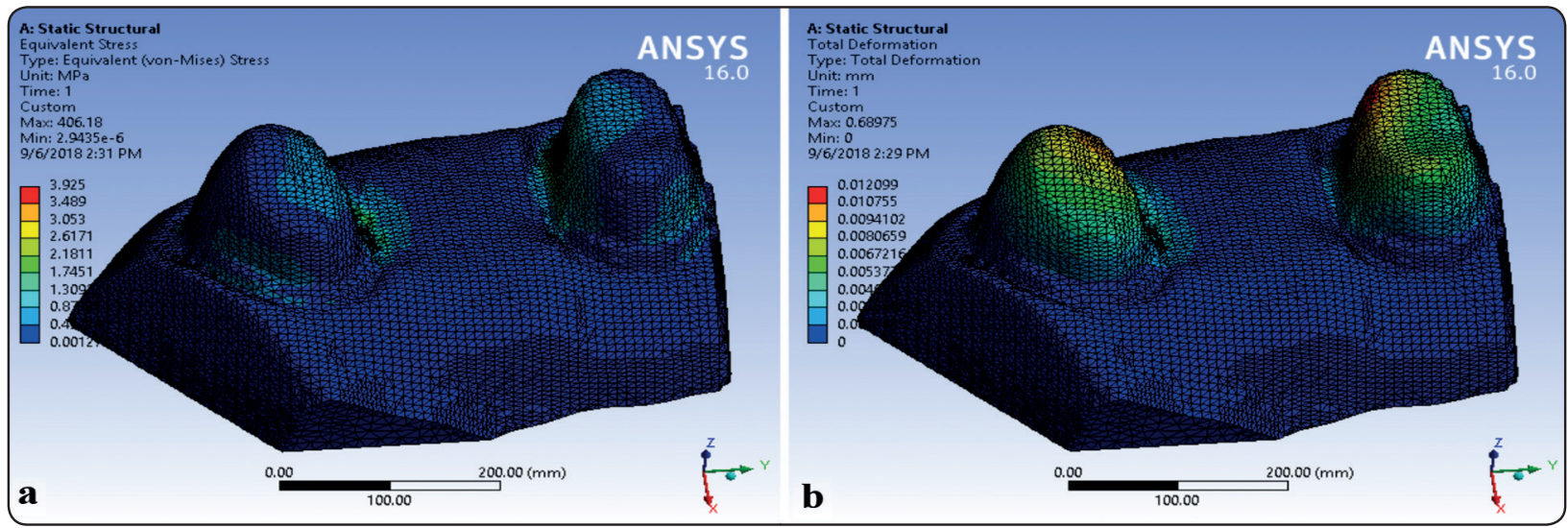

Fig. (8) Tooth under (PEEK) (FDP), (a) Von Mises stress and (b) total deformation. 


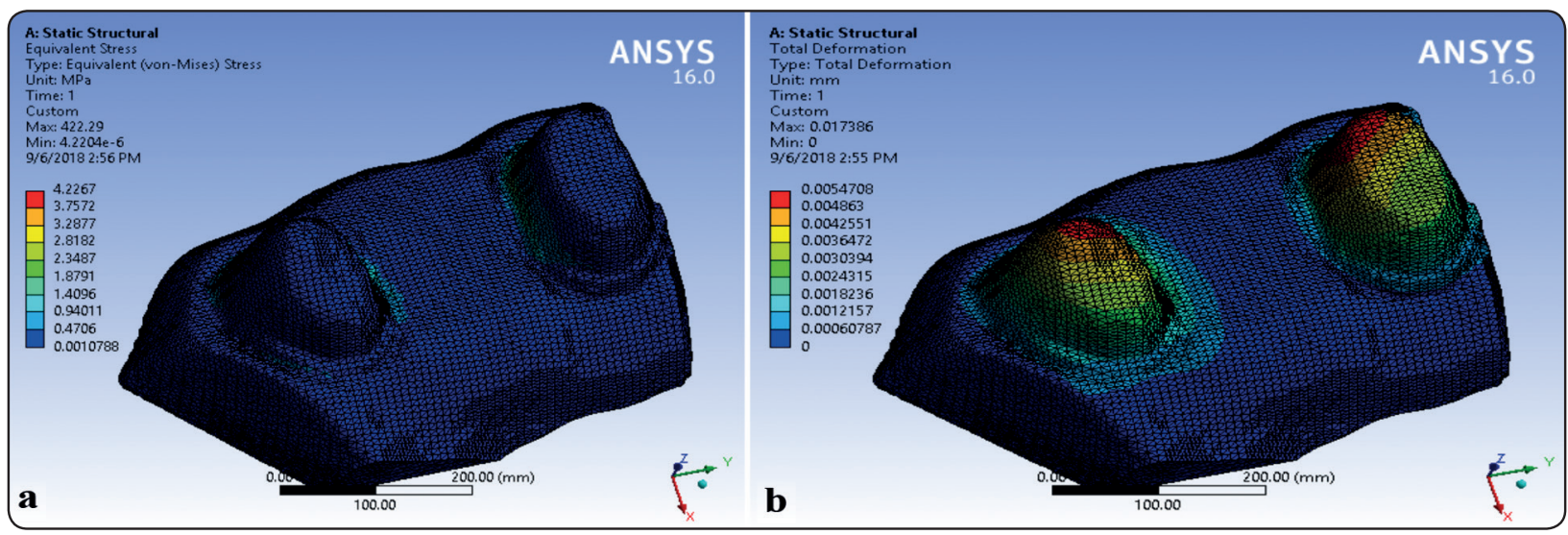

Fig. (9) Tooth under (Zircon) (FDP), (a) Von Mises stress and (b) total deformation.

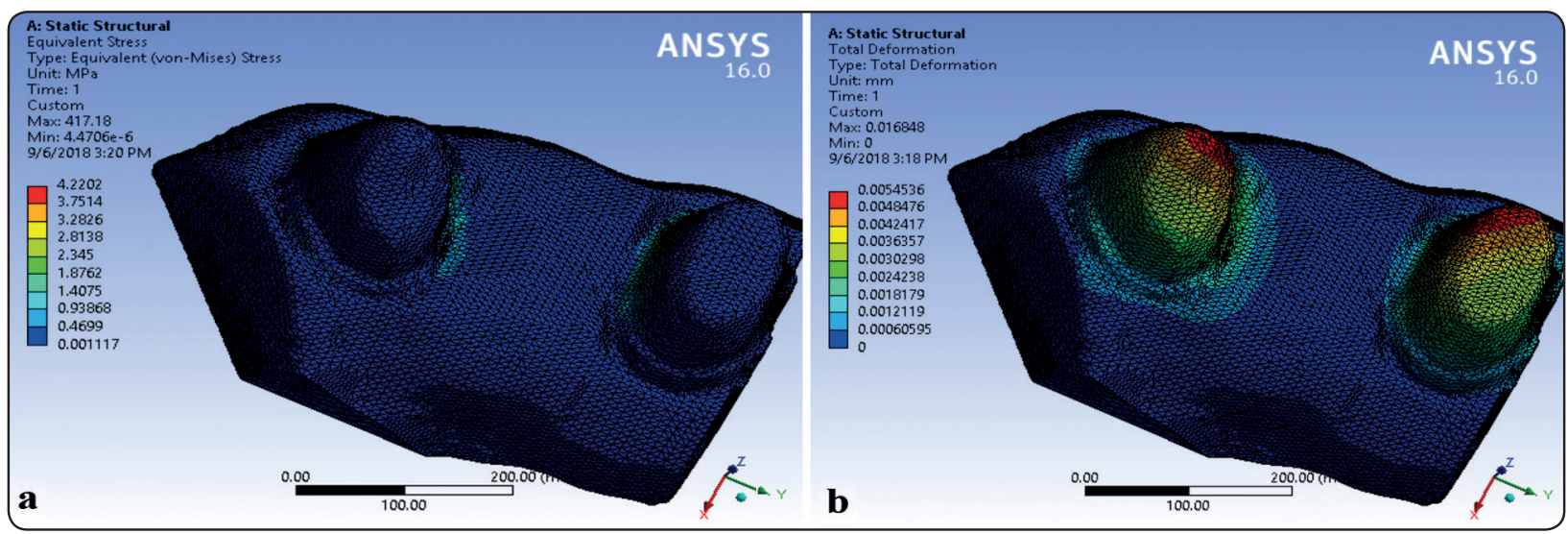

Fig. (10) Tooth under (Ni-Cr) (FDP), (a) Von Mises stress and (b) total deformation.

\section{DISCUSSION}

Stress distribution around teeth with healthy periodontium and the replacing restorative materialare a debated issue in the recent literature. ${ }^{(20-22)}$ The stress distribution in a (FDP) depends on its geometric configuration and material properties. ${ }^{(15)}$

Several materials have been used in order to restore missing posterior teeth in terms of function and esthetics. ${ }^{(23,24)}$ Metals such as (Ni-Cr) are used successfully for many years for fabricating (FDP) frameworks because of their durability, versatility and low cost. (5) Zirconia-ceramic restorations are preferred and may be considered as a viable alternative to metal frameworks because of their desirable esthetics, excellent biocompatibility and superior fracture toughness and strength, when compared to other all-ceramic systems; however, because of their brittleness, a catastrophic fracture may occur with or without plastic deformation when they are subjected to a critical tensile load. ${ }^{(25)}$

Several studies revealed that zirconia shows superior mechanical properties adequate for use in posterior restoration. ${ }^{(26-32)}$ Schmitter et al. ${ }^{(33)}$ investigated 30 extended zirconia frameworks and 5 of them showed fracture. In another study by Schmitter et al. ${ }^{(34)} 8$ examples of 30 extended zirconia frameworks showed fracture. In our study we concluded that the maximum stress values in 3-unit tooth-supported fixed zirconia (FDP) were 
(422MPa), whereas the ultimate strength value of zirconia (900-1200 MPa), so a fracture could be considered inevitable.

Recently, (PEEK) restorations have been introduced with adequate mechanical properties and a modulus of elasticity similar to that of bone, enamel and dentin, enabling it as a viable treatment option for permanent (FDPs). ${ }^{(35)}$

The purpose of this investigation was to investigate the effect of different framework materialson the stress distribution in posterior (FDPs). It was recommended that the use of (FEA) should be applied, when possible, to complement mechanical property evaluation in which stresses were developed. Moreover, these preliminary analysis could greatly facilitate the design of in vitro experiments involving ceramics and reduce the total testing time by eliminating test that are unlikely to be fruitful. ${ }^{(36)}$

In this study, a qualitative analysis of stress distribution using Von Mises criteria and principle stresses to measure the overall stresses was performed. It should be mentioned that Von Mises stress is a formula for combining the three uniaxial stresses: tensile, compressive and shear stresses ( $x$, $y$, and $z$ planes). ${ }^{(37)}$ If these stresses are more than the yield strength of the material, catastrophic fracture will occur. The maximum and minimum stresses are recorded to show areas of compression and tension. ${ }^{(1)}$

In designing a (FDP), the displacement of the span in relation to the space under the(FDP) should be considered, because excessive deformation can result in compression of the gingival tissues. The deformation of a(FDP) can be controlled by the modulus of elasticity of the framework material.

In this study, based on the numerical analysis of the investigated (FDPs), it was determined that the total deformation of the (PEEK) (FDP) with the lowest Young's modulus of (3-4 GPa) was
$(689 \mu)$, while for (Ni-Cr) and Zirconia (FDPs) were $(16.8,17.3 \mu$, respectively); however, all materials were considered predictable and safe for use in the posterior region.Analysis of the (FDP) deformation results under the influence of a vertical load showed that a (FDP) with high Young's (elastic) modulus (220GPa), critical vertical displacement was reduced by an average of 40-43\%; moreover, the close results of (Ni-Cr) and Zirconia (FDPs) could be attributed to the very close material properties. These results are in accordance with Reimann et al. ${ }^{(38)}$ who stated that deflection of (FDPs) depend on the material's modulus of elasticity and connector configuration.

In the present study, Von Mises stresses developed in the (Ni-Cr), Zircon, (PEEK) frameworks were (417,422,406 $\mathrm{MPa}$, respectively) (Figures 4-6). The Von Mises stresses developed in the (PEEK) framework were close to the material yield stress that indicates short life time for this (FDP) material; however, these values were within the safe limits of the materials used, which ensured the safe use of all tested materials for restoration of missing posterior teeth.

Several clinical studies have demonstrated that zirconia-based ceramics are considered suitable substructures to withstand the high tensile stresses that occurin multi-unit (FDPs). ${ }^{(39-43)}$ In metalceramic (FDPs) the metal framework provides the sufficient strength to resist occlusal forces. Romeed, et al. ${ }^{(44)}$ stated that that the highest value of principal stress in all materials should be less than the relevant critical value to avoid material failure. Some researchers in the implant fieldrevealed that a more resilient superstructure material could reduce stresses around the implant by the elastic deformation behavior of the material. ${ }^{(45)}$ On the contrary, there are studies that reported changing the superstructure material did not affect the stress levels. ${ }^{(46)}$ 
It has been reported that the mean adult occlusal force is about $400-800 \mathrm{~N}$ at the molar region, $300 \mathrm{~N}$ at the premolar region, and $200 \mathrm{~N}$ in the anterior region. ${ }^{(40)}$ In the present study, a load of $200 \mathrm{~N}$ was chosen, if greater loads were done, the maximum value would be expected to scale directly with the increasing load as the modeling conducted here was an elastic analysis. This study was designed to evaluate the stress distribution rather than to determine the strength of the FPDs; therefore, the applied load will not affect the major findings of this study. Under these loading conditions, the highest Von Mises stresses found in this study were localized in the finish line towards the missing tooth (pontic) for all the materials.

The use of different dental cements has an impact on the stress distribution of crown, cement layer, and prepared tooth. Dental cement with a high modulus of elasticity creates a wider distribution of a higher stress concentration area within the cement layer. ${ }^{(47)}$ Several authors have studied the role of dental cement by using (FEA). Proos et al. ${ }^{(48)}$ investigated the influence of adhesive resin and ZPC on In-Ceram coping and gold coping, and their findings revealed that the type of dental cement has a minor effect on the resultant stress distribution. Shahrbaf et al. ${ }^{(49)}$ studied the influence of the tooth preparation design and the elastic modulus of 4 different resin cements, and they found that both the preparation design and the elastic modulus of cement affect the stress distribution of the restored crown-root complex.

In the present study, adhesive resin cement with a standardized thickness $(40 \mu \mathrm{m})$ was used because it showed low stress concentration in the cement layer and has the advantages of low modulus of elasticity, low solubility, high tensile strength, high compressive strength, and high bonding strength. ${ }^{(47)}$ The stress values developed in the cement layer were higher in the (PEEK) framework (9.82 $\mathrm{MPa}$ ), followed by Zirconia and (Ni-Cr) frameworks
(4.56, 4.53 MPa, respectively); however, the cement layer was safe from failure under the applied load of $200 \mathrm{~N}$, whatever the framework material. These are coincident with the results of HA SR. ${ }^{(47)}$ who suggested that low elastic materials result in a lower stress distribution in the cement layer and transfer less stresses to the prepared tooth.

On the abutment tooth, only slight differences in maximal principal stress were observed (Table 3 and 4). Highest values were (4.227 MPa) for Zirconia, (4.220 MPa) for (Ni-Cr), and (3.925 MPa) for (PEEK). This could be attributed to the shock absorbing effect of the material. Stresses transferred to the abutment teeth were within physiological limits under all the tested (FDP) materials under the compressive load of $200 \mathrm{~N}$. The results showed that maximum deformation appeared on the highest surface (s) of the prepared teeth in all materials. Once again, the finish line received the maximum Von Mises stresses that were located towards the pontic (Figures 8-10). This result was in accordance with El-Banna et al. ${ }^{(39)}$ who found that in two cases of missing tooth (FDP) restoration as cantilever or fixed-fixed (FDP), the finish line received the maximum stresses towards the missing tooth. In addition, the obtained results showed that tooth was insensitive to the (FDP) materials. This finding was in accordance with Kao H. et al. ${ }^{(50)}$ who claimed that the majority of the developing stresses were concentrated in the frameworks and less stresses were within the natural teeth adjacent to the test site.

There were some limitations in the present study which made the obtained values may not correlate closely to values measured intraorally. In our study, three different framework materials were evaluated, but the veneering materials were not evaluated to simulate the clinical condition. All tested materials were considered isotropic, continuous and elastic, which differs from the clinical condition, ${ }^{(14)}$ we didn't consider the periodontal ligament as it is a very small element with hyper-elastic proprieties, which 
are very difficult to represent in the 3D model;thus, a complex non-linear study is the resultant; however, this is a comparative study between three different materials, so it is not essential. Another limitation was the direction and mode of occlusal loading. All loads in this study were applied axially at the center of the pontic; although, oblique loading has been suggested to represent a realistic occlusal load. ${ }^{(19)}$ Therefore, further investigations that better simulate the oral environment and including fatigue loading are recommended.

\section{CONCLUSIONS}

Within the limitations of this study, the following conclusions were drawn:

1. A fixed dental prosthesis has critical point with maximum value of Von Mises stresses at finish line towards missing tooth. Therefore, finish line contact with (FDP) should have superior care to avoid such stress concentration.

2. Tooth: tooth deformation and stresses were within physiological limits

3. Cement layer: Rigid (FDP) material (as Ni-Cr and Zirconia) transfer loads to cement much better than resilient (FDP) material (PEEK).

4. Fixed dental prosthesis: (FDP) material showed minor differences in stresses, while (PEEK) (FDP) deformation was about four times the rigid ones deformation.

\section{ACKNOWLEDGEMENT}

Authors would like to express their deep thanks to Prof. Dr. Mohamed El-Anwar (Mechanical Engineering Dept. National Research Centre) for their great effort during this study.

\section{REFERENCES}

1. Yossef SA, Galal RM, Alqahtani WM, Alluqmani AA, Abdulsamad MA, Alsharabi OH, Smurgandi EM. Comparison between two materials for the fabrication of modified design for posterior inlay retained fixed dental prosthesis: A finite element study. J Int Oral Health 2018; 10:88-93.

2. Pjetursson BE, Brägger $\mathrm{U}$, Lang NP, Zwahlen $\mathrm{M}$ Comparison of survival and complication rates of toothsupported fixed dental prostheses (FDPs) and implantsupported FDPs and single crowns (SCs). Clin Oral Implants Res 2007; 18:97-113.

3. Lang, N. P., Pjetursson, B. E., Tan, K., Bragger, U., Egger, M., \& Zwahlen, M. (2004). A systematic review of the survival and complication rates of fixed partial dentures (FDPs) after an observation period of at least 5 years. II. Combined tooth implant-supported FDPs. Clinical Oral Implants Research 2004; 15, 643-653.

4. Raigrodski AJ, Hillstead MB, Meng GK, Chung K-H: Survival and complications of zirconia-based fixed dental prostheses: A systematic review. J Prosthet Dent 2012; 107: 170-177.

5. Motta AB, Pereira LC, da Cunha ARCC, Duda FP: The influence of the loading mode on the stress distribution on the connector region of metal-ceramic and all-ceramic fixed partial denture. Artif Organs 2008; 32: 283-291.

6. Raigrodski AJ, Chiche GJ, Potiket $\mathrm{N}$ et al: The efficacy of posterior three-unit zirconium-oxide-based ceramic fixed partial dental prostheses: A prospective clinical pilot study. J Prosthet Dent 2006; 96: 237-244.

7. Miura S, Kasahara S, Yamauchi S, Egusa H: Threedimensional finite element analysis of zirconia allceramic cantilevered fixed partial dentures with different framework designs. Eur J Oral Sci 2017; 125: 208-214.

8. Bacchi A, Consani RLX, Mesquita MF, dos Santos MBF: Stress distribution in fixed-partial prosthesis and periimplant bone tissue with different framework materials and vertical misfit levels: A three-dimensional finite element analysis. J Oral Sci 2013; 55: 239-244.

9. Möllers K, Pätzold W, Parkot D, Kirsten A, Güth JF, Edelhoff D, Fischer H. Influence of connector design and material composition and veneering on the stress distribution of all-ceramic fixed dental prostheses: A finite element study. Dent Mater 2011; 27: e171-175.

10. Borba M, Duan Y, Griggs JA, Cesar PF, Della Bona A. Effect of ceramic infrastructure on the failure behavior and stress distribution of fixed partial dentures. Dent Mater 2015: 31: 413-422. 
11. Zoidis P, Bakiri E, Polyzois G. Using modified polyetheretherketone (PEEK) as an alternative material for endocrown restorations. J Prosthet Dent 2017; 117:335-339.

12. Schmidlin PR, Stawarczyk B, Wieland M, Attin T,Hammerle CHF, Fischer J. Effect of different surface pretreatments and luting materials on shear bond strength to PEEK. Dent Mater 2010; 26:553-559.

13. Stawarczyk B, Jordan P, Schmidlin PR, Roos M,Eichberger M, Gernet W. PEEK surface treatment effects on tensile bond strength to veneering resins. J Prosthet Dent 2014; 112:1278-1288.

14. Rzanny A, Göbel R, Fachet M. BIO HPP Summary of results for material tests. Quintessenz Zahntech MAG 2013; 39:2-10.

15. Wang G, Zhang S, Bian C, Kong H. Verification of finite element analysis of fixed partial denture with in vitro electronic strain measurement. J Prosthodont Res 2016; 60:29-35.

16. Silva N. R. F. A., Bonfante E. A., Zavanelli R. A., Thompson V. P., Ferencz J. L., Coelho P. G. Reliability of metalloceramic and zirconia-based ceramic crowns. J Dent Res. 2010; 89:1051-1056.

17. Jafari K, Vojdani M, Mahdavi F, Heidary H. Finite Element Analysis of the Effect of Superstructure Materials and Loading Angle on Stress Distribution around the Implant. J Dent Biomater 2014; 1:57-62.

18. Ayse Kocak-Buyukdere, Atilla Sertgoz and Cem Dergin. Finite Element Analysis of 3 and 4 Units Zirconium Fixed Partial dentures. Madridge J Dent Oral Surg 2016; 1: 20-25.

19. Geng JP, Tan KB, Liu GR. Application of finite element analysis in implant dentistry: a review of the literature. $\mathrm{J}$ Prosthet Dent 2001; 85:585-598.

20. Alhasanyah A, Vaidyanathan TK, Flinton RJ. Effect of core thickness differences on post-fatigue indentation fracture resistance of veneered zirconia crowns. J Prosthodont. 2013;22:383-390.

21. Augstin-Panadero R, Fons-Font A, Roman-Rodriguez JL, et al. Zirconia versus metal: a preliminary comparative analysis of ceramic veneer behavior. Int $\mathrm{J}$ Prosthodont 2012; $25: 294-300$.

22. Meriç G., Erkmen E., Kurt A., Eser A., Ozden A.U. Biomechanical comparison of two different collar structured implants supporting 3-unit fixed partial denture: A 3-D FEM study. Acta Odontol. Scand 2012; 70:61-71.
23. G. J. Christensen, Porcelain-fused-to-metal versus zirconia based ceramic restorations, J Am Dent Assoc 2009; 140: 1036-1039.

24. Bindl A., Luthy H., Mormann W.H. Thin-wall ceramic CAD/CAM crown copings: Strength and fracture pattern. J. Oral Rehabil 2006; 33:520-528.

25. Triwatana P., Nagaviroj N., Tulapornchai C. Clinical performance and failures of zirconia-based fixed partial dentures: A review literature. J Adv Prosthodont 2012; 4:76-83.

26. Tsumita M, Kokubo Y, Ohkubo C, Sakurai S, Fukushima S. Clinical evaluation of posterior all-ceramic FPDs (Cercon): a prospective clinical pilot study. J Prosthodont Res 2010; 54:102-105.

27. Sailer I, Gottnerb J, Kanelb S, Hammerle CH. Randomized controlled clinical trial of zirconia-ceramic and metalceramic posterior fixed dental prostheses: a 3-year followup. Int J Prosthodont 2009;22:553-560

28. Sadan A, Blatz MB, Lang B. Clinical considerations for densely sintered alumina and zirconia restorations: part 1 . Int J Periodontics Restorative Dent 2005; 25:213-219.

29. Sadan A, Blatz MB, Lang B. Clinical considerations for densely sintered alumina and zirconia restorations: part 2. Int J Periodontics Restorative Dent 2005; 25:343-349.

30. Beuer F, Edelhoff D, Gernet W, Sorensen JA. Three-year clinical prospective evaluation of zirconia-based posterior fixed dental prostheses (FDPs) Clin Oral Investig 2009; 13:445-451.

31. Raigrodski AJ, Yu A, Chiche GJ, Hochstedler JL, Mancl LA, Mohamed SE. Clinical efficacy of veneered zirconium dioxide-based posterior partial fixed dental prostheses: five-year results. J Prosthet Dent 2012; 108:214-222.

32. Ortorp A, Kihl ML, Carlsson GE. A 5-year retrospective study of survival of zirconia single crowns fitted in a private clinical setting. J Dent 2012; 40:527-530.

33. Schmitter M, Mussotter K, Rammelsberg P, et al. Clinical performance of extended zirconia frameworks for fixed dental prostheses: two-year results. J Oral Rehabil 2009; 36:610-615.

34. Schmitter M, Mussotter K, Rammelsberg P, et al. Clinical performance of long-span zirconia frameworks for fixed dental prostheses: 5-year results. J Oral Rehabil 2012; 39:552-557. 
35. Georgiev J, Vlahova A, Kissov Ch, Aleksandrov S, Kazakova R. Possible application of BioHPP in prosthetic dentistry: a literature review. J of IMAB 2018; 24:18961898.

36. Anusavice KJ, Kakar K, Ferree N. Which mechanical and physical testing methods are relevant for predicting the clinical performance of ceramic-based dental prostheses? Clin Oral Impl Res 2007; 18: 218-231.

37. Durand LB, Guimaraes JC, Monteiro Junior S, Baratieri LN. Effect of ceramic thickness and composite bases on stress distribution of inlays--a finite element analysis. Braz Dent J 2015; 26:146-151.

38. Reimann Ł, Żmudzki J, Dobrzański LA. Strength analysis of a three-unit dental bridge framework with the Finite Element Method Acta Bioeng Biomech 2015;17:51-59.

39. El-Banna KA,El-Anwar MI, Salem SK. Fracture resistance of two all ceramic posterior fixed partial dentures designs: a finite element analysis. Egy Dent J 2014; 60: 3303-3312.

40. Lüthy H, Filser F, Loeffel O, Schumacher M, Gauckler LJ, Hammerle CH. Strength and reliability of four-unit allceramic posterior bridges. Dent Mater 2005; 21:930-937.

41. Oh W, Götzen N, Anusavice KJ. Influence of connector design on fracture probability of ceramic fixed-partial dentures. J Dent Res 2002; 81:623-627.

42. Oh W, Anusavice KJ. Effect of connector design on the fracture resistance of all-ceramic fixed partial dentures. J Prosthet Dent 2002; 87:536-542.

43. Sundh A, Molin M, Sjorgen G. Fracture resistance of yttrium oxide partially-stabilized zirconia all-ceramic bridges after veneering and mechanical fatigue testing. Dent Mater 2005; 21:476-482.

44. Romeed SA, Fok SL, Wilson NHF. Finite element analysis of fixed partial denture replacement. J Oral Rehabil 2004; 31:1208-1217.

45. Erkmen E, Meriç G, Kurt A, Tunç Y, Eser A. Biomechanical comparison of implant retained fixed partial dentures with fiber reinforced composite versus conventional metal frameworks: A 3D FEA study. J Mech Behav Biomed Mater 2011; 4:107-116.

46. Cehreli MC, Akça K, Iplikçioğlu H. Force transmission of one- and two-piece morse-taper oral implants: a nonlinear finite element analysis. Clin Oral Implants Res. 2004; 15:481-489.

47. Ha SR. Biomechanical three-dimensional finite element analysis of monolithic zirconia crown with different cement type. J Adv Prosthodont 2015; 7:475-483.

48. Proos KA, Swain MV, Ironside J, Steven GP. Influence of cement on a restored crown of a first premolar using finite element analysis. Int J Prosthodont 2003; 16:82-90.

49. Shahrbaf S, vanNoort R, Mirzakouchaki B, Ghassemieh E, Martin N. Effect of the crown design and interface lute parameters on the stress-state of a machined crowntooth system: a finite element analysis. Dent Mater 2013; 29:e123-131.

50. Kao H., Chung W., Chen F., Hsu M., and Chang K.; Finite Element analysis of different superstructure materials in a single distal implant restoration, J Dent Sci 2008; 3:140149. 